\title{
In-situ observations of dissolution process of GaSb into InSb melt by $\mathrm{X}$-ray penetration method
}

\author{
G.Rajesh $^{\text {a) }}$, M.Arivanandhan ${ }^{\text {a) }}$, H.Morii ${ }^{\text {a) }}$, T.Aoki ${ }^{\text {a) }}$, T.Koyama ${ }^{\text {a) }}$, Y.Momose ${ }^{\text {a) }}$, \\ A.Tanaka ${ }^{\text {a) }}$, T.Ozawa ${ }^{\text {b) }}$, Y.Inatomi ${ }^{\text {c) }}$ and Y.Hayakawa ${ }^{\text {a), * }}$ \\ ${ }^{\text {a }}$ Research Institute of Electronics, Shizuoka University, Johoku 3-5-1, Naka-ku, \\ Hamamatsu, Shizuoka 432-8011, Japan \\ ${ }^{\mathrm{b}}$ Department of Electrical Engineering, Shizuoka Institute of Science and Technology, \\ Fukuroi, Shizuoka 437-8555, Japan \\ ${ }^{\mathrm{c}}$ Institute of Space and Astronautical Science, Japan Aerospace Exploration Agency, \\ 3-1-1 Yoshinodai, Sagamihara, Kanagawa 229-8510, Japan
}

\footnotetext{
* Corresponding author:

Yasuhiro Hayakawa

Research Institute of Electronics, Shizuoka University, 3-5-1 Johoku, Naka-ku, Hamamatsu 432-8011, Japan

Tel/Fax: +81-053-478-1310

Email: royhaya@ipc.shizuoka.ac.jp
} 


\begin{abstract}
Dissolution process of GaSb into InSb melt was observed by X-ray penetration method. The intensity of X-rays penetrated through the rectangular shaped GaSb (seed)/InSb/GaSb (feed) sandwich sample was recorded by the CdTe line sensor detector. The penetrated X-ray intensities and images of the sample were obtained as a function of time and temperature. The gallium (Ga) composition profile of the sample was calculated as a function of time by making the calibration line with the penetrated X-ray intensities of GaSb and InSb standard samples. The calculated Ga composition profile of the grown sample was well agreed with the data measured by energy dispersive X-ray spectroscopy analysis. The result suggested that lower GaSb seed was dissolved faster than upper GaSb feed despite of low temperature at the lower GaSb seed. It clearly indicates that the solutal transport induced by gravity strongly affects the dissolution process.
\end{abstract}

PACS: 78.70.Ck; 81.10.-h; 81.10.Dn; 8.10.Mx

Keywords: A1. Mass transfer; A2 Growth from solutions; B1. Gallium compounds; B2. Semiconducting III-V materials 


\section{Introduction}

$\mathrm{In}_{\mathrm{x}} \mathrm{Ga}_{1-\mathrm{x}} \mathrm{Sb}$ is a promising III-V alloy semiconductor, highly useful for optoelectronic devices as well as thermo photovoltaic applications, since the wavelength and lattice constant of $\operatorname{In}_{\mathrm{x}} \mathrm{Ga}_{1-\mathrm{x}} \mathrm{Sb}$ can be adjusted between 1.7 6.8 $\mu \mathrm{m}$ and 6.09 6.48 $\AA$, respectively by changing the composition ratio [1]. However, crystal growth of crack-free homogeneous InGaSb alloy crystals from the melt is extremely difficult [2]. The following two factors mainly affect the growth of homogeneous $\operatorname{In}_{x} \mathrm{Ga}_{1-\mathrm{x}} \mathrm{Sb}$ crystal. First one is the segregation effect which results wide composition variations along the growth direction of the crystal. Second is the solute and heat transfer which strongly affects the quality of the crystal [3]. To grow a homogeneous $\operatorname{In}_{\mathrm{x}} \mathrm{Ga}_{1-\mathrm{x}} \mathrm{Sb}$ crystal, in-situ observation of the dissolution process, composition profile, growth process and the shape of the solidliquid interface are very important.

Many authors have been studied the above mentioned vital growth parameters for various materials using different techniques. Lent et al. [4] performed a mathematical simulation of travelling solvent method (TSM) growth of GaInSb under suppressed gravity conditions. They found that the position of the thermal profile severely disturbed the characteristics and stability of the growing crystal [4]. Okano et al. [5] applied TSM to the numerical modeling of a simulation for the growth of GaSb from a Ga-solution. They investigated the effects of crucible temperature, crucible rotation and crucible material on the solid-liquid interface shape [5]. Ye et al. investigated the effects of natural convection on temperature and solute distributions, growth rate and growth uniformity along the interface for CdTe single crystal by TSM growth [6]. Tsukamoto et al. 
measured the composition profile near the growth interface in the aqueous solution by laser interferometry technique $[7,8]$. However, it is very difficult to measure the composition profile in the metallic solution since the light cannot penetrate into it. Kakimoto et al. [9] analyzed solid-liquid interface shape by X-ray radiography method during crystal growth of $\mathrm{Si}$ as the X-rays can penetrate into $\mathrm{Si}$ melt. Inatomi et al. investigated the morphological stability of solid-liquid interface in semiconductor crystal growth from solution using near-infrared microscopic interferometer [10, 11]. Tanaka et al. directly observed the growth of $\mathrm{GaAs}$ on a GaP substrate using a liquid-phase epitaxial growth system with a long distance microscope [12]. Ujiihara et al. investigated the in-situ measurement of composition of a Ga-Zn solution in a carbon crucible by X-ray fluorescence spectrometer [13]. The same authors were investigated the solute and temperature distributions in the Zn-Ga-Zn alloy solutions by combining the X-ray fluorescence spectroscopy and the infrared camera [14]. They observed that the zinc distribution changed due to the diffusion in the temperature gradient and consequently reached the stationary state. Sazaki et al. investigated the in-situ quantitative measurement of the solution temperature distribution during the solution growth of SiGe bulk crystal using an infrared camera [15]. They observed the position of the growth interface and also measured the temperature around the growth interface. Azuma et al. [16] and Usami et al. [17] grew the SiGe bulk crystal with uniform composition by directly controlling the growth temperature at the crystal-melt interface using infrared camera. However, when compared to binary compounds, the dissolution process and growth kinetics are more complicated for ternary compounds. Due to fundamental as well as increasing technological importance of the III-V alloy semiconductors, it is 
indispensable to understand the growth kinetics of the material by means of in-situ observations. In this point of view, Hyakawa et al. [18] observed the diffusion process of $\mathrm{NH}_{4} \mathrm{Br}$ into $\mathrm{H}_{2} \mathrm{O}$ as a function of time by $\mathrm{X}$-ray penetration method using a CdTe detector and the penetrated X-ray intensity was converted to the $\mathrm{NH}_{4} \mathrm{Br}$ composition using a calibration line. Based on the above method, indium composition profiles in the In-GaSb solution were measured using the cylindrical shaped $\mathrm{GaSb} / \mathrm{InSb} / \mathrm{GaSb}$ sandwich sample [18]. In addition, they have investigated the growth rate and the solid-liquid interface shape of the $\operatorname{In}_{x} \mathrm{Ga}_{1-\mathrm{x}} \mathrm{Sb}$ crystals by using heat pulse technique and numerical simulation [19-22]. Further investigations are needed to understand the dissolution and growth process, more in detail. In the present study, the in-situ observations of dissolution process of GaSb into InSb melt were investigated and Ga composition profile of the In-Ga-Sb solution using a rectangular shaped $\mathrm{GaSb} / \mathrm{InSb} / \mathrm{GaSb}$ sandwich sample was obtained by X-ray penetration method. From the results, we have made clear the effect of gravity on the dissolution process.

\section{Experimental method}

Fig. 1 shows the sample configuration and the inside temperature profile of the furnace with a dummy sample. Rectangular shaped GaSb(seed)/InSb/GaSb(feed) sandwich sample was used for the experiment. The dimensions of GaSb (seed, feed) and InSb samples were $6 \times 6 \times 3 \mathrm{~mm}^{3}$ and $6 \times 3 \times 3 \mathrm{~mm}^{3}$ (W $\mathrm{x} \mathrm{L \times} \mathrm{H)}$, respectively. The samples were polished with alumina abrasive powder and etched in an acid mixture of $\mathrm{HNO}_{3}: \mathrm{HF}: \mathrm{CH}_{3} \mathrm{COOH}(1: 1: 1)$ to remove the oxide layer. To observe the dissolution 
process and composition profile of the sample, it should be holded in a proper crucible material, which is transparent to X-rays. In the present investigation, boron nitride (BN) and quartz were selected as a transparent material for X-rays since the absorption by both of them was very small compared with GaSb and InSb. The sandwich sample covered by BN tube was inserted into the quartz ampoule and the ampoule was evacuated about $10^{-4}$ Pa before sealing. The sealed ampoule was fixed into the furnace vertically. The inside temperature profile at the centre of the ampoule was measured by using a dummy sample with a central hole along the growth axis. The temperature profile in the furnace at the ampoule position was measured by connecting the CA thermocouples inside a dummy sample at the lower seed end and upper feed end before the X-ray penetration experiment. With respect to the reference temperature $650^{\circ} \mathrm{C}$, the inside temperatures of lower seed end and upper feed end were measured as $525.2^{\circ} \mathrm{C}$ and $581.7^{\circ} \mathrm{C}$, respectively. The temperature gradient at the sample position was fixed as $3.7^{\circ} \mathrm{C} / \mathrm{mm}$. The upper $\mathrm{GaSb}$ feed was set up at high temperature region and lower GaSb seed was set up at low temperature region. During the experiment, the thermocouple was connected at the middle of the furnace for the measurement of reference temperature. The temperature of the furnace was monitored by using the reference temperature. Since the sample was covered by the BN tube and quartz ampoule, the sample temperature would be reasonably varied from the reference temperature.

Fig. 2 shows the X-ray penetration measurement system configuration. The furnace was fixed on a platform, which can be moved along the three directions $\mathrm{x}, \mathrm{y}, \mathrm{z}$ and can be rotated along $360^{\circ}$. X-ray source is the tungsten target with an acceleration voltage $150 \mathrm{kV}$ and the current $0.1 \mathrm{~mA}$. The detector is a rectangular shape CdTe line 
sensor which has 64 cells in x-direction and 1510 cells in y-direction. The size of the each cell is $0.1 \mathrm{~mm}$. So the total active area of the detector is $6.4 \mathrm{~mm} \times 151 \mathrm{~mm}$.

In order to get the relationship between the $\mathrm{X}$-ray intensity and $\operatorname{In}_{\mathrm{x}} \mathrm{Ga}_{1-\mathrm{x}} \mathrm{Sb}$ composition, the solid and liquid X-ray penetration intensities of the GaSb and InSb standard samples were measured. By making the calibration line between the penetrated X-ray intensities of the GaSb and InSb standard samples, $\operatorname{In}_{\mathrm{x}} \mathrm{Ga}_{1-\mathrm{x}} \mathrm{Sb}$ composition was measured. To observe the dissolution and growth process, the standard sample was replaced by GaSb (seed)/InSb/GaSb (feed) sandwich sample. During the experiment, the distance between the X-ray source and the sample was fixed as $315 \mathrm{~mm}$, and the distance between the X-ray source and the detector was fixed as $815 \mathrm{~mm}$. As a result, the image of the sample was magnified about 2.58 times on the detector. Since each cell size of the detector was $0.1 \mathrm{~mm}$, the resolution of the detector was about $0.038 \mathrm{~mm}$.

Fig. 3 shows the reference temperature program for the experiment. The temperature of the furnace was raised up to $650^{\circ} \mathrm{C}$ and it was maintained as constant for 1hr $20 \mathrm{~min}$. From $450^{\circ} \mathrm{C}$, the X-rays were allowed to penetrate through the sample and the penetrated X-ray intensities were continuously recorded for every one second to insitu observe the melting and dissolution process clearly. InSb was completely melted when the temperature reached $640^{\circ} \mathrm{C}$. By maintaining the temperature at $650^{\circ} \mathrm{C}$, the dissolution of GaSb into InSb melt was increased until the solution became saturated. Once the dissolution was stopped, the temperature was slowly decreased from $650^{\circ} \mathrm{C}$ to $640^{\circ} \mathrm{C}$ and maintained as constant for $1 \mathrm{hr} 20 \mathrm{~min}$ to observe the growth from seedsolution interface. 
The penetrated X-ray intensities were continuously recorded up to $550^{\circ} \mathrm{C}$ during post-growth cooling. Finally, the sample was cooled down to room temperature (RT) and the X-ray intensity through the solidified sample was recorded for one second. The grown sample was cut parallel to the growth direction and polished with an alumina abrasive powder. The Ga composition profile of the grown sample was measured along the growth direction by the Energy Dispersive X-ray Spectroscopy (EDS) analysis.

\section{Result and discussion}

Fig. 4 shows the combined X-ray images of the sample as a function of time. The figure recorded at RT shows the image of the solid $\mathrm{GaSb}$ (seed)/InSb/GaSb(feed) sandwich sample. The light blue region and dark blue region indicate the GaSb and InSb, respectively. Since the X-ray penetration intensity of InSb is smaller than that of GaSb, the InSb region in the image looks darker blue compared with GaSb region. The penetrated X-ray intensities and images of the sample were recorded for every one second from the temperature $450^{\circ} \mathrm{C}$ (starting time of $\mathrm{X}$-ray exposure). The solid and liquid densities of the GaSb and InSb were tabulated (Table 1).While increasing the temperature, InSb was melted at $640^{\circ} \mathrm{C}$ in $4 \mathrm{~min}$. During this phase transition, volume of InSb melt was reduced due to the density variation from the solid to liquid of InSb (Table 1). The molten region becomes darker compared with solid region due to relatively low X-ray penetrated intensity than that of InSb solid. Once the InSb was completely melted, the temperature was maintained as constant at $10^{\circ} \mathrm{C}$ above the melting reference temperature of $\mathrm{InSb}\left(650^{\circ} \mathrm{C}\right)$ for the enhancement of dissolution of $\mathrm{GaSb}$ into InSb melt. 
From 7 min 30 sec, lower GaSb seed and upper GaSb feed were started to dissolve into the InSb melt and hence the seed and feed interface positions were moved towards the lower GaSb seed and upper GaSb feed, respectively. After 7 min 42 sec, only the seed-interface was continued to shift towards the lower GaSb as the dissolved amount of GaSb seed increases. On the other hand, upper feed-interface was almost in the same position. It indicates that, after $7 \mathrm{~min} 42 \mathrm{sec}$ the dissolution of upper feed into InSb melt was suppressed and the dissolution of lower seed into InSb melt was enhanced. The dissolved upper GaSb feed was remained just below the feed-interface due to the smaller density of GaSb liquid and it became a stable GaSb-rich layer. The small layer of GaSbrich and lighter dense melt below the upper GaSb feed-interface prevents buoyant convection thereby the transportation of the heavier dense solvent molecule (InSb) towards the feed interface was suppressed. Therefore, the further dissolution of upper GaSb-feed into InSb melt was suppressed. Moreover, solutal convection due to the density differences and thermal convection due to the temperature gradient are having an opposing effect. However, density of a solution at the high temperature is smaller than that at the low temperature and hence the convective instability due to the temperature gradient is negligible. Therefore, the dissolved GaSb from the seed-interface moved towards the upper region by solutal convection, which originates from the density variations of liquid GaSb and liquid InSb (Table 1). As a result, the dissolution of lower GaSb-seed into InSb melt was increased as the availability of solvent molecules (InSb) is larger at the lower region (near the seed-solution interface). It clearly indicates that the diffusion was dominant at the upper feed-interface; on the other hand, solutal convection was dominant at the lower seed-interface. At $8 \mathrm{~min}$, In-Ga-Sb solution region further 
increased and seed-interface was shifted towards the lower GaSb seed as the concentration gradient at the lower GaSb seed-interface was steeper than that of upper GaSb feed-interface. From 9 to 10 min, only a small amount of GaSb was dissolved into solution. It indicates that, initially the dissolution of GaSb was faster and then it was decreased with time. After $10 \mathrm{~min}$, there was no change in the interface position but the Ga composition near the seed interface gradually decreased due to the diffusion and convection in the solution. From the Fig. 4, we clearly observed that lower GaSb seed was dissolved faster than upper GaSb feed even though the lower GaSb seed temperature was smaller than that of upper GaSb feed temperature. The X-ray images (Fig.4) clearly indicate that gravity induced solutal convection plays the major role during the dissolution process of GaSb into InSb melt.

The Ga composition profile of the solution was measured by making the calibration line between the liquid intensities of GaSb and InSb standard samples. Fig.5 (a), (b), (c), (d) and (e) show the Ga composition profile of the In-Ga-Sb solution at $7 \mathrm{~min}$ $30 \mathrm{sec}, 7 \mathrm{~min} 42 \mathrm{sec}, 8 \mathrm{~min}, 10 \mathrm{~min}$ and $15 \mathrm{~min}$, respectively. All the profiles were compared with the InSb melt (7 min) profile to illustrate the dissolution process clearly. In the x-axis of the Fig.5, the distance between 0 to $6 \mathrm{~mm}$ shows the initial lower $\mathrm{GaSb}$ seed position, the distance from 6 to $9 \mathrm{~mm}$ and 9 to $15 \mathrm{~mm}$ shows the initial $\mathrm{InSb}$ position and initial upper GaSb feed position, respectively.

In Fig. 5. (a), the 7 min data shows the Ga composition profile after InSb was melted. The length of InSb melt was reduced to $2 \mathrm{~mm}$ from the InSb solid length of $3 \mathrm{~mm}$ due to density variation between solid and liquid of InSb. From the X-ray penetration method, the reduction of the volume change from solid to liquid was clearly seen. From 
the 7 min 30 sec data, it is obvious that the lower GaSb seed and the upper feed were started to dissolve into InSb melt. So, the Ga composition in the In-Ga-Sb solution was gradually increased from lower GaSb seed and upper feed to the InSb melt. In Fig. 5 (b), the solute transport from the lower GaSb seed to the upper GaSb feed interface was enhanced, therefore, seed-solution interface position was almost $1 \mathrm{~mm}$ shifted towards lower seed end. On the other hand, solute transport from upper GaSb feed was suppressed due to the accumulation of the lighter GaSb component at the feed-solution interface. About $1 \mathrm{~mm}$ of lower GaSb seed was dissolved in the solution; as a result Ga composition profile was changed.

From the 8 min data shown in Fig. 5 (c), Ga composition of the solution further increased as the lower GaSb seed was further dissolved (almost $2 \mathrm{~mm}$ ) into the solution and the dissolved Ga solute transported to the solution by solutal convection as well as diffusion. Therefore, the Ga composition gradually decreased from the seed interface to the middle of the solution as shown in Fig. 5 (c). As shown in Fig. 5 (d), Ga composition near the seed-solution interface was decreased and it was increased near the middle of the solution. It clearly indicates that the solute transport from the lower side to upper side. As can be seen from the Fig.5 (e), it was observed that there is no change in the interface position but the Ga composition profile was changed; it indicates that the dissolution became slower and the dissolved GaSb from the seed moved-up in the solution and the dissolved GaSb from the feed was diffused into the solution. The results clearly indicate that Ga composition profile of the solution and the length of In-Ga-Sb solution region changed with the dissolved GaSb composition. 
After the X-ray penetration experiment, the Ga composition profile of the grown sample was measured by the X-ray penetration method and also the grown sample was subjected into the EDS analysis in order to confirm the dissolved region of $\mathrm{GaSb}$ into the InSb melt. Fig. 6 shows the Ga composition profiles of the grown sample measured by EDS analysis and X-ray penetration method. The triangular and rectangular points show the Ga composition profile measured by EDS analysis and X-ray penetration method, respectively. The distance between 0 to $3.1 \mathrm{~mm}$ shows the undissolved lower part of the GaSb seed. It shows that about $2.9 \mathrm{~mm}$ of lower GaSb seed was dissolved into the InSb melt since the initial length of lower GaSb seed was $6 \mathrm{~mm}$. The distance between $7.5 \mathrm{~mm}$ to $13.2 \mathrm{~mm}$ shows the undissolved upper part of the GaSb feed. It shows that only about $0.3 \mathrm{~mm}$ of upper GaSb feed was dissolved into the InSb melt. It indicates that lower GaSb seed was dissolved larger than upper GaSb feed. The distance between $3.1 \mathrm{~mm}$ to $7.5 \mathrm{~mm}$ shows the dissolved region of GaSb into InSb melt i.e. In-Ga-Sb region. The data of the X-ray penetration method also reflect almost the same Ga composition profile and the dissolved region of $\mathrm{GaSb}$ into the InSb melt as obtained by EDS analysis. Ga composition profile and dissolved region of the grown sample obtained by the X-ray penetration method was confirmed by EDS analysis. Moreover, the results suggest that the X-ray penetration method is more reliable to observe the dissolution process and the composition profile in the metallic solution. As a future task, the growth process of the $\mathrm{In}_{\mathrm{x}} \mathrm{Ga}_{1-\mathrm{x}} \mathrm{Sb}$ will be observed by in-situ measurement technique. 


\section{Conclusion}

The dissolution process of GaSb into InSb melt was observed by X-ray penetration method. GaSb (seed)/InSb/GaSb (feed) sandwich sample was used for the experiment. The lower GaSb seed was dissolved faster than upper GaSb feed even though the lower GaSb seed temperature was smaller than that of upper GaSb feed temperature. The dissolved GaSb from the seed moved to the upper region due to solutal convection since the liquid GaSb density was smaller than that of liquid InSb. On the contrary, the dissolved upper GaSb was remained just below the interface of the upper GaSb feed. So, most of the GaSb components were accumulated at the feed interface which suppressed the further dissolution of GaSb feed. Therefore, the dissolution of GaSb seed into InSb melt was enhanced. Ga composition profile of the solution was measured as a function of time by using X-ray penetration intensities. The dissolution region of $\mathrm{GaSb}$ into InSb melt was confirmed by measuring the Ga composition of the grown sample using EDS analysis. It revealed the same result as observed by X-ray penetration method. The experimental results clearly show that the dissolution of GaSb into InSb melt and solute transport in In-Ga-Sb solution were strongly influenced by gravity induced solutal convection.

\section{Acknowledgement}

One of the authors, G.Rajesh, would like to thank Japan Ministry of Education, Culture, Sports, Science, and Technology for financial support. The part of the work has 
been done by the cooperative research project of the Research Institute of Electronics, Shizuoka University. 


\section{References}

[1] N. Murakami, K. Arafune, T. Koyama, M. Kumagawa, Y. Hayakawa, J. Cryst. Growth 275 (2005) 433.

[2] P.S. Dutta, A.G. Ostrogorsky, J. Cryst. Growth 194 (1998) 1.

[3] Y. Hayakawa, K. Balakrishnan, K. Arafune, T. Ozawa, Y. Okano, A. Hirata, M. Kumagawa, Microgravity experiments on dissolution and crystallization of InGaSb, in: Y.Hayakawa, Y.Furukawa (Eds.), Studies on Crystal Growth under Microgravity, Resaerch Signpost Inc, India, 2005, pp.1-50.

[4] B. Lent, S. Dost, R.F. Redden, Y. Liu, J. Cryst. Growth 237-239 (2002) 1876.

[5] Y. Okano, S.S. Nishino, S.S Ohkubo, S. Dost, J. Cryst. Growth 237-239 (2002) 1779.

[6] X. Ye, B. Tabarrok, D. Walsh, J. Cryst. Growth 169 (1996) 704.

[7] K. Tsukamoto, in: I. Sunagawa (Ed.), Morphology and Growth Unit of Crystals, Terra Scientific Publishing Company, 1989, pp. 451- 478.

[8] K. Tsukamoto, E. Yokoyama, S. Maruyama, K. Maiwa, K. Shimizu, R.F. Sekerka, T.S. Morita, S. Yoda, J. Jpn. Soc. Microgravity Appl. 15 (1998) 2.

[9] K. Kakimoto, M. Eguchi, H. Watanabe, T. Hibiya, J. Cryst. Growth 91 (1988) 509.

[10] Y. Inatomi, K. Kuribayashi, Cryst. Res. Technol. 38, [7-8], (2003) 535.

[11] Y. Inatomi, K. Kikuchi, R. Nakamura, K. Kuribayashi, I. Jimbo, J. Cryst. Growth 275 (2005) 193.

[12] A. Tanaka, N. Izumi, M. Kimura, T. Sukegawa, J. Cryst. Growth 208 (2000) 33.

[13] T. Ujihara, G. Sazaki, S. Miyashita, N. Usami, K. Nakajima, Jpn. J. Appl. Phys. 39 (2000) 5981. 
[14] T. Ujihara, K. Fujiwara, G. Sazaki, N. Usami, K. Nakajima, J. Cryst. Growth 242 (2002) 313.

[15] G. Sazaki, Y. Azuma, S. Miyashita, N. Usami, T. Ujihara, K. Fujiwara, Y. Murakami, K. Nakajima, J. Cryst. Growth 236 (2002) 125.

[16] Y. Azuma, N. Usami, T. Ujihara, G. Sazaki, Y. Murakami, S. Miyashita, K. Fujiwara, K. Nakajima, J. Cryst. Growth 224 (2001) 204.

[17] N. Usami, Y. Azuma, T. Ujihara, G. Sazaki, S. Miyashita, Y. Murakami, K. Nakajima, Jpn. J. Appl. Phys. 40 (2001) 4141.

[18] Y. Hayakawa, T. Hikida, H. Mori, A. Konno, C.H. Chen, K. Arafune, H. Kawai, T. Koyama, Y. Momose, T. Ozawa, T. Aoki, J. Cryst. Growth 310 (2008) 1487.

[19] N. Murakami, K. Arafune, T. Koyama, M. Kumagawa, Y. Hayakawa, J. Cryst. Growth 263 (2004) 320.

[20] N. Murakami, T. Hikida, A. Konno, K. Arafune, T. Koyama, Y. Momose, T. Ozawa, M. Miyazawa, M. Kumagawa, Y. Hayakawa, J. Cryst. Growth 310 (2008) 1433.

[21] Y. Hayakawa, Y. Okano, A. Hirata, N. Imaishi, Y. Kumagiri, X. Zhong, X. Xie, B. Yuan, F. Wu, H. Liu, T. Yamaguchi, M. Kumagawa, J. Cryst. Growth 213 (2000) 40.

[22] T. Kimura, K. Arafune, K. Balakrishnan, T. Ozawa, Y. Okano, N. Murakami, H. Adachi, Y. Hayakawa, M. Kumagawa, J. Cryst. Growth 247 (2003) 291. 


\section{Figure captions:}

Figure 1 Sample configuration and inside temperature profile of the furnace measured with a dummy sample.

Figure 2 X-ray measurement system configuration.

Figure 3 Reference temperature program for the experiment.

Figure 4 X-ray images of the sample as a function of time.

Figure 5 Ga composition profile of the In-Ga-Sb solution (a) 7 min and $7 \mathrm{~min} 30 \mathrm{sec}$, (b) $7 \mathrm{~min}$ and $7 \mathrm{~min} 42 \mathrm{sec}$, (c) $7 \mathrm{~min}$ and $8 \mathrm{~min}$, (d) $7 \mathrm{~min}$ and $10 \mathrm{~min}$, (e) 7 min and 15 min.

Figure 6 The Ga composition profiles of the grown sample measured by EDS analysis and X-ray penetration method. 
Table 1. Solid and liquid densities of the GaSb and InSb.

\begin{tabular}{|l|l|l|}
\hline Compound & $\begin{array}{l}\text { Solid Density } \\
\left(\mathrm{g} / \mathrm{cm}^{3}\right)\end{array}$ & $\begin{array}{l}\text { Liquid Density } \\
\left(\mathrm{g} / \mathrm{cm}^{3}\right)\end{array}$ \\
\hline GaSb & 5.61 & 6.01 \\
\hline InSb & 5.78 & 6.32 \\
\hline
\end{tabular}



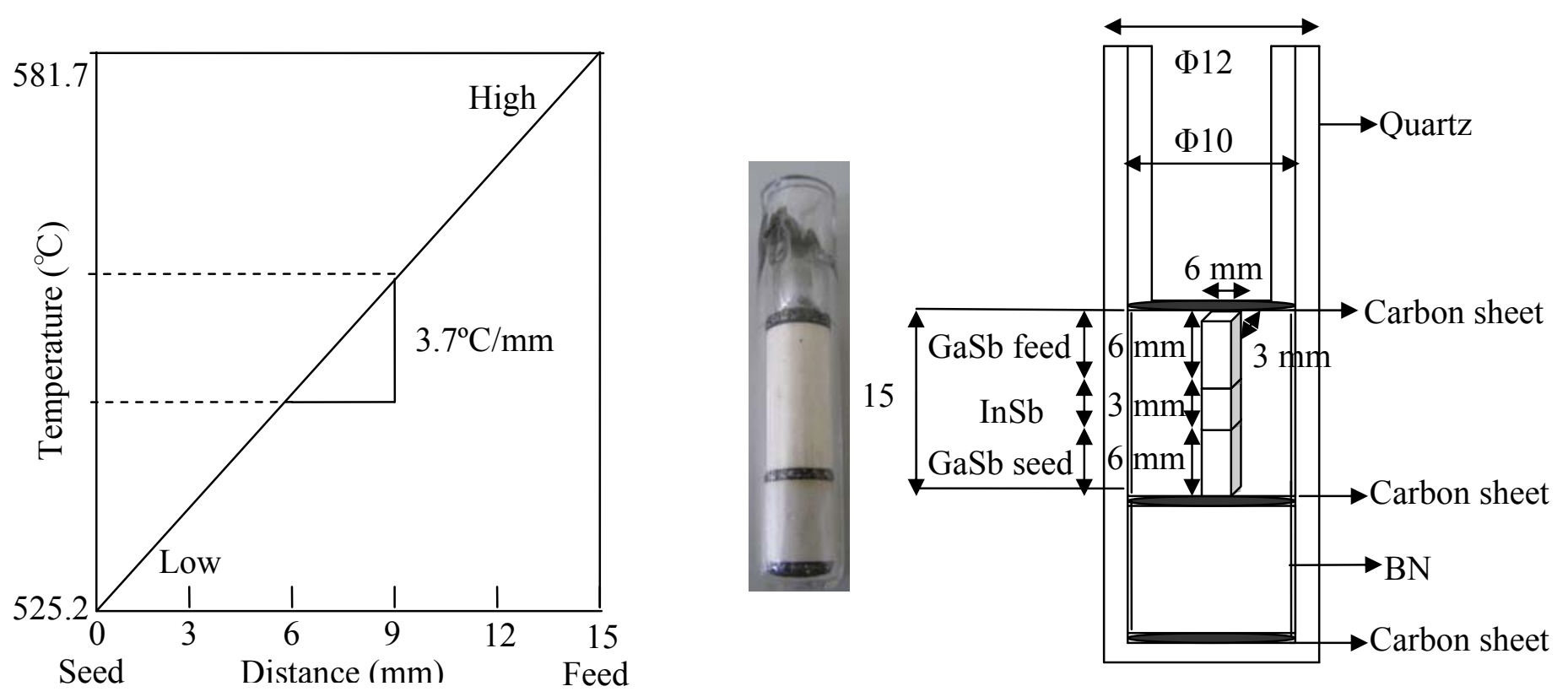

Figure 1 

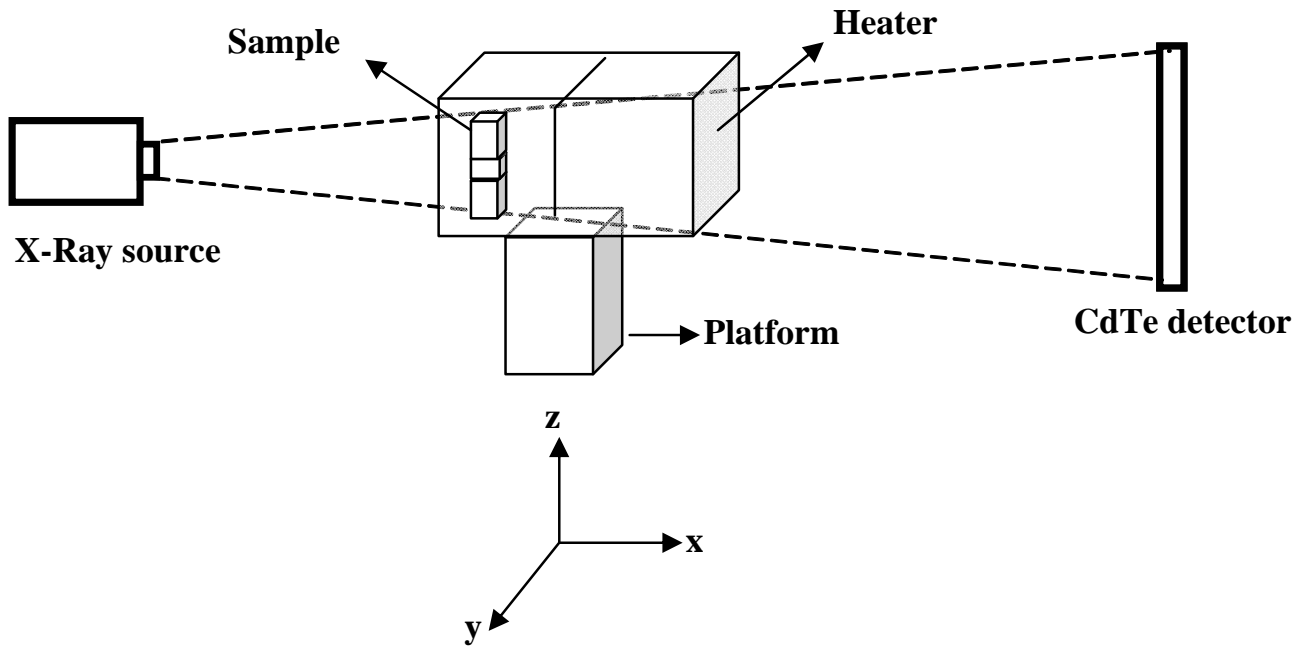

Figure 2 


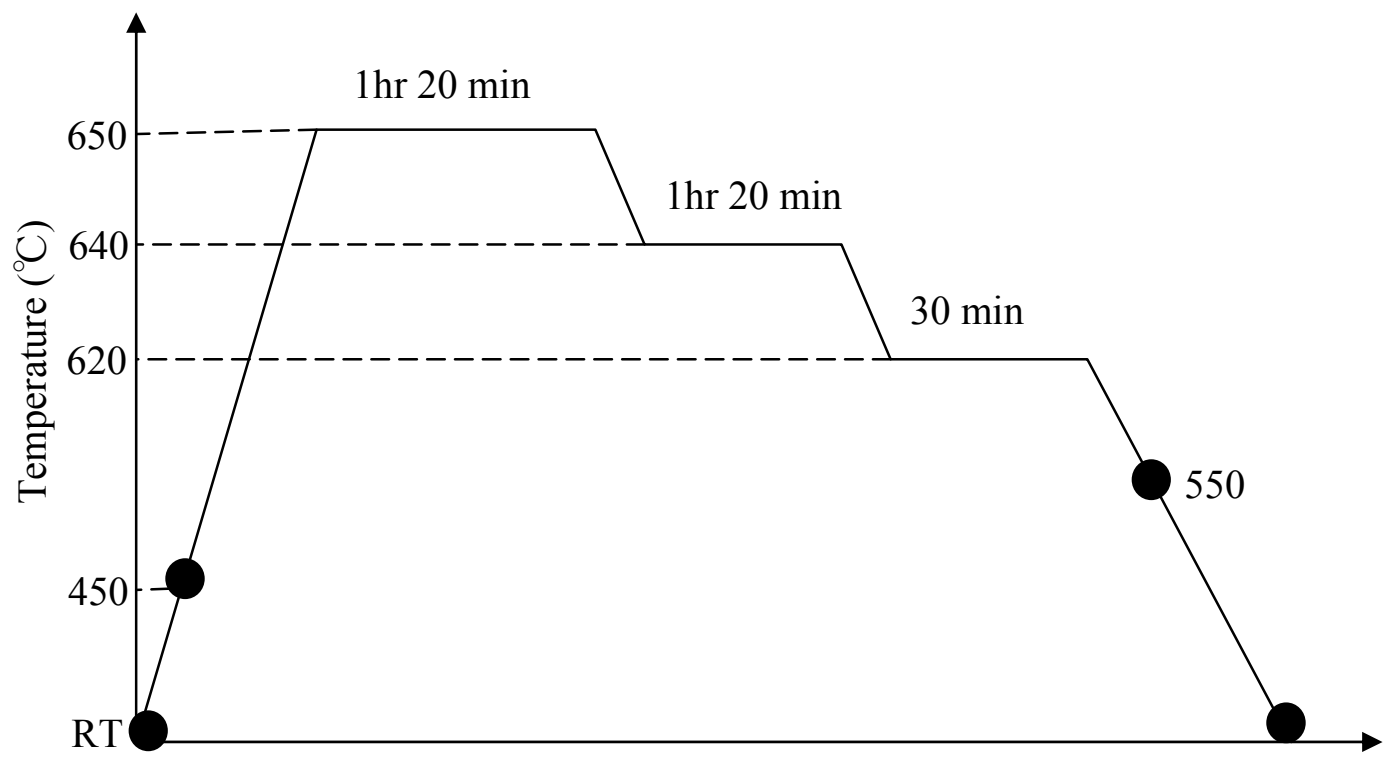

Time (min)

Figure 3 
Temperature $\left({ }^{\circ} \mathrm{C}\right)$

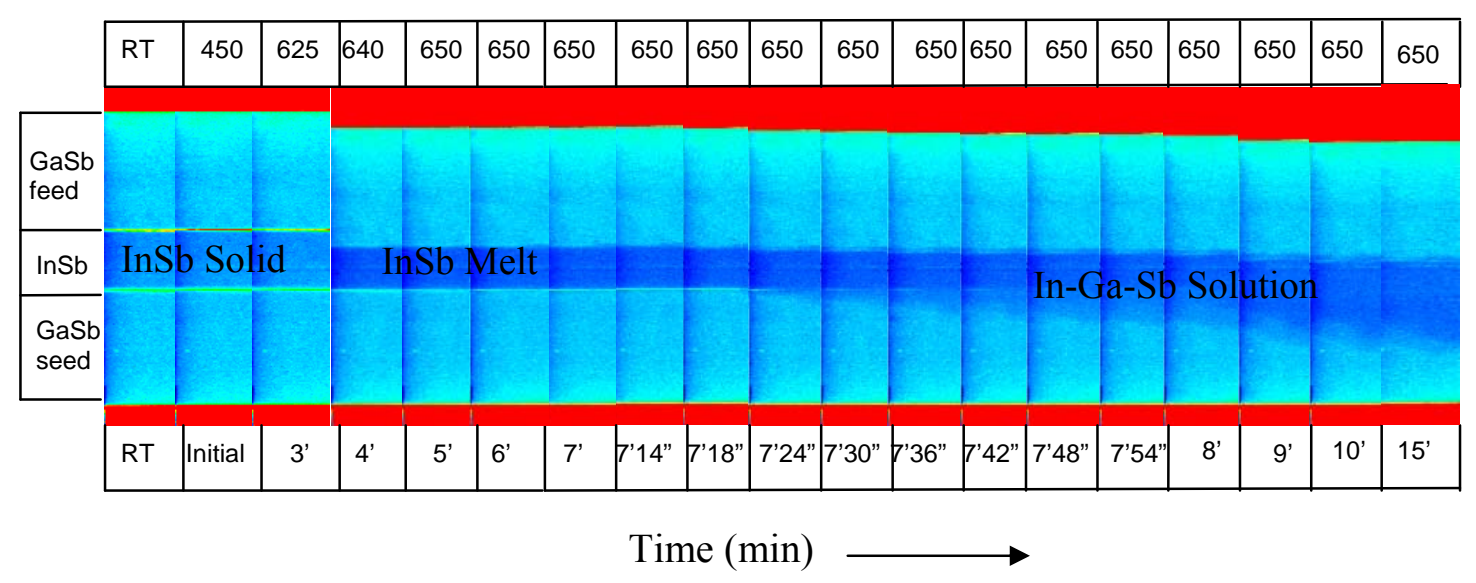

Figure 4

Color in print 

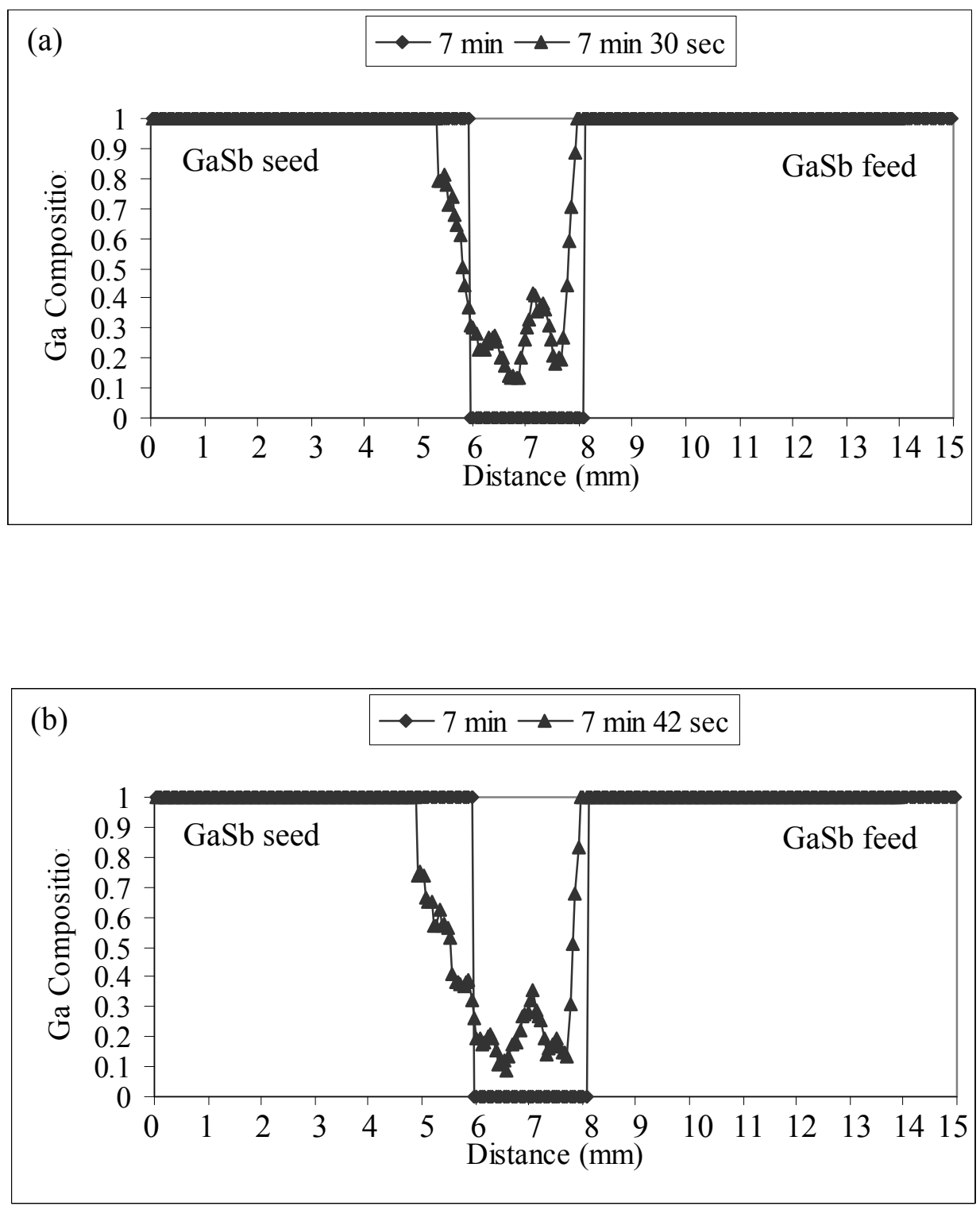

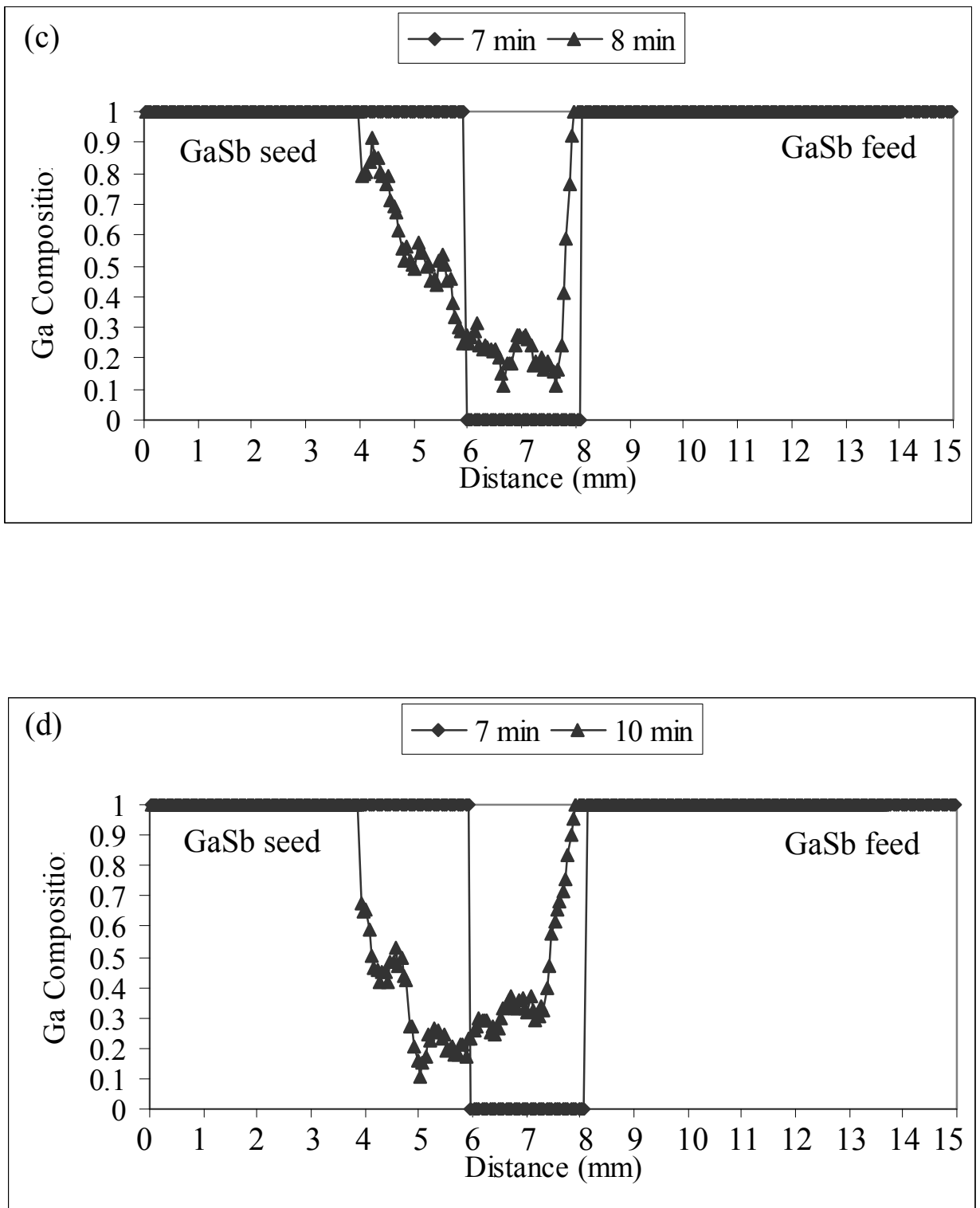


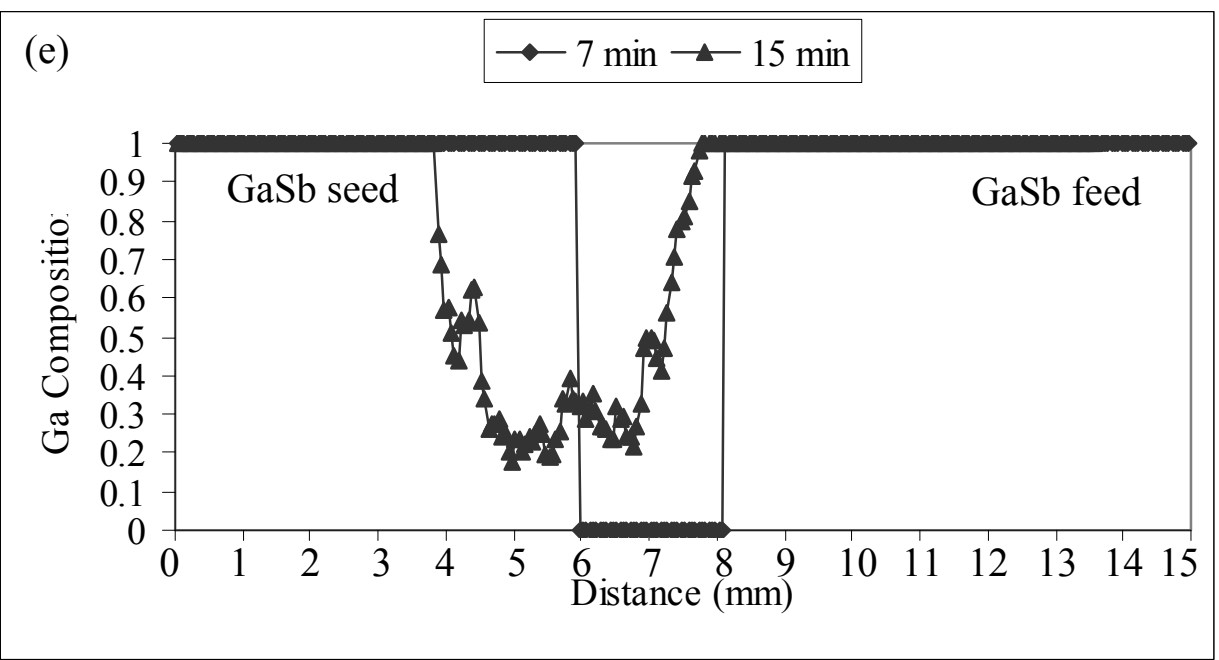




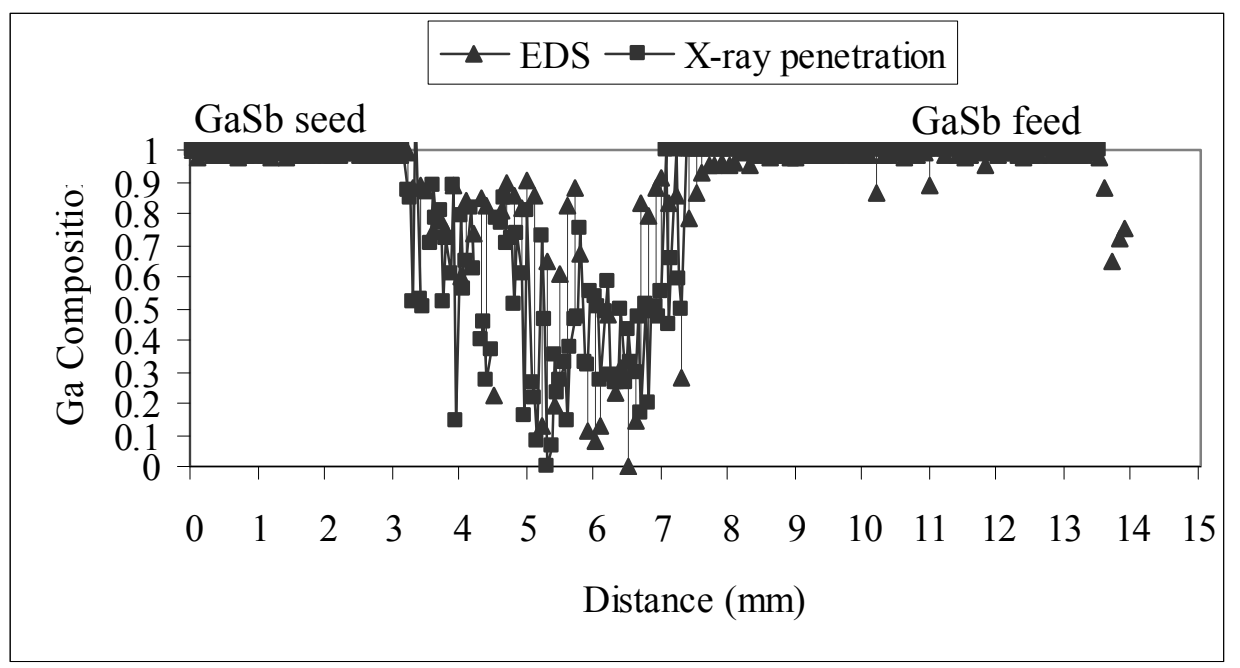

Figure 6 